
$\frac{252.458 \times 1728}{4375}=997^{\circ} 137$ oz. Av. ; hence we may as-

sume that the entire weight of water which fell on one square mile was $\frac{52,086,144 \times 997^{\circ} 137}{35,840}=1,449,136$ tons, $(\div 984=1,472,699$ milliers $)$. Some idea of this enormous quantity will be afforded by the following illustrations.

The Thames at London Bridge is, at low water, nearly 700 feet wide, ${ }^{*}$ and from 12 to 13 (say 12.5 ) feet deep. We will, for the sake of argument, assume the sectional area throughout to be $700 \times 125=8.750$ square feet. The amount of rainfall on a square mile was equivalent to a volume of water corresponding in sectional area to the Thames at London Bridge, and extending $\frac{52,086,144}{8750 \times 5280}=$ I.127 miles in length; in other words, it would extend from London Bridge, past Cannon Street (Railway), Southwark and Blackfriars (Railway and Road) Bridges, to about Somerset House, or nearly to Waterloo Bridge.

The same quantity of water would equal the contents of a river or canal having an uniform width of 20 feet, and depth of 5 feet-the sectional area being roo feet--extending nearly 99 miles, or I 59 kilometres in length.

The cubic contents of a sphere are $\frac{2}{3}$ of that of a cylinder of the same diameter and altitude. But the altitude being equal to the diameter, and 2 of 7854 being . 5236 , the contents may be expressed as $I$ have arranged it in the following formula. Calling $\triangle$ the diameter, and $x$ the cubic contents required, we have

$$
\triangle^{3} \times 5236=x
$$

or the reverse, calling $\mathrm{C}$ the cubic contents and $x$ the diameter required.

$$
\sqrt[3]{\frac{C}{5236}}=x
$$

By these formulæ I have determined that the rainfall on a square mile-under the conditions mentioned in paragraph 3 -was equivalent to a globe of water $463 \mathrm{ft}$. in diameter (approximate), a height exceeding that of the top of the cross surmounting the dome above the pavement of the churchyard of St. Paul's Cathedral (370 ft. $\dagger$ ) by $93 \mathrm{ft}$.

The same quantity of water was equivalent to the following :-

A circular column of water $\mathrm{I} 44 \mathrm{ft}$. in diameter (corresponding to that of the dome of St. Paul's Cathedral-interior surface + ), rising to a height of $3,198 \mathrm{ft}$; in other words, it would be upwards of $8 \frac{1}{2}$ times the height of the cross before-mentioned.

Or, with regard to specific gravity :-

A circular column of lead (cast) § of the same diameter ( $144 \mathrm{ft}$. - a cubic foot being taken as 7 Iolbs., or I I, $360 \mathrm{oz}$.) containing 4,571,92I cubic ft., and rising to a height of $278 \mathrm{ft}$.

A circular column of granite (Aberdeen) of the same diameter, a cubic foot being taken as $2,690 \mathrm{oz}$., containing $19,307,443$ cubic feet, and rising to a height of $\mathrm{I}, \mathrm{I} 84 \mathrm{ft}$.

But perhaps the most remarkable illustration will be afforded by comparing the weight of this quantity of water to a corresponding weight contained in, say, a number of railway coal waggons. Railway coal waggons are constructed to carry, on an average, from eight to ten tons. Let us assume it as the former of the two, and the average length of a number of waggons as 16 feet

* I quate this from a paper "On the Rainfall of Devonshire," by W. Pengelly, Esq., F.R.S., Scientific Opinior, Vol. i. p. I37. (From the Transactions of the Devonshire Association for the Advancement of Science, 1868 . The depth is confirmed in the Encyclopadia Britanica, Vol. xxi p. $x 6_{3}$. † Encyclopadtia Brittanica, yol. xiii. p. 670

From the Cathedral authorities. "Sprague's Pocket Tables (Architects and Surveyors)," p. 9.
Ibid. each from buffer to buffer. It would require no less than 181, 142 such waggons to carry a corresponding weight of coal (or 3,623 heavy trains of fifty waggons each) which would, when close coupled, i.e., buffer to buffer, extend over a distance of nearly 549 miles (883 kilometres) represented very nearly by the distance from London (Euston Station) to Aberdeen viâ Rugby, Stafford, Crewe, Carlisle, Glasgow, and. Perth (London and North Western and Caledonian Railways). An express train, travelling at an uniform speed of sixty miles per hour, would take upwards of nine hours to run this distance, in other words, to pass this number of waggons ; or, if I may indulge in another illustration, this number of waggons would, if travelling at an uniform rate of twenty-five miles per hour-which is about the average rate of goods trainsbe nearly twenty-two hours in passing any given point such, for instance, as a station. (Aberdeen is upwards of 130 miles N.N.E. of Edinburgh by the Caledonian Railway - Eastern route from London.)

Such a means of illustration as the one I have here set forth may not be considered in all respects strictly scientific; it has nevertheless this advantage, it enables us to comprehend something of the truth and magnitude of the subject-although dealing with hypotheses-where mere abstract figures would fail to produce anything like a similar result.

JOHN JAMES HALI.

\section{ON CERTAIN PHENOMENA ASSOCIATED WITH A HYDROGEN FLAME}

PHENOMENA of much interest and possibly of future usefulness are associated with the combustion of ordinary hydrogen.

I. To study these phenomena free from disturbing causes three things should be attended to, although the effects to be described can be obtained without any special precaution.

(a) The gas must be stored and purified in the ordinary way, namely, by passing into a gas-holder through a solution of potash, and then through a solution of perchloride of mercury or nitrate of silver.

(b) From the holder the gas must be led through red or black india-rubber tubing to a platinum, or better, a steatite jet.

(c) And then the gas should be burnt in a perfectly dark room, and amid calm and dustless air.

II. In this way the flame gives a faint reddish brown colour, invisible in bright daylight. Issuing from a narrow jet in a dark room, a stream of luminosity, more than six times the length of the flame, is seen to stretch upward from the burning hydrogen. This weird appearance is probably caused by the swifter flow of the particles of gas in the centre of the tube. The central particles as they shoot upward are protected awhile by their neighbours; metaphorically, they are hindered from entering the fiery ordeal which dooms then finally to a watery grave. Dr. Tyndall has shown that the radiation from burning hydogen is hugely ultra-red, and moreover, that it has not the quality of the radiation from an elementary body like hydrogen, but practically is found to be the radiation from molecules of incandescent steam. So that, except at its base, a hydrogen flame is a hollow stream of glowing water raised to a prodigious heat.

III. Bringing the flame into contact with solid bodies, in many cases phosphorescent effects are produced. Thus allowing the flame to play for a moment on sand paper and then promptly extinguishing the gas, a vivid green, phosphorescence remains for some seconds. The appearance is a beautiful one, as a luminous and perfect section of the hollow flame is depicted. Similar phosphorescence is produced by the flame on white writing paper, 
or on marble, or chalk, or granite, or gypsum, \&c. But no such effect is produced by coal gas, or olefiant or marsh gas. It is evidently a question of temperature, as oxygen given through coal gas shows the phosphorescence well.

IV. Far exceeding in generality the effect just noticed is a really magnificent blue image of the flame that starts up on almost every substance with which the flame is brought into contact. I have already drawn attention to this effect in the Phil. Mag. for November 1865, and in my letter of last week pointed out how the same effect has more recently formed the subject of a memoir, presented through M. 'Wurtz to the Paris Academy of Sciences, the author of that paper evidently being unaware that the subject had already been investigated by myself.

The appearance is as follows: When the hydrogen flame is brought either vertically or sideways, say, upon a white plate or a block of marble, there instantly appears a deep blue and glowing impression of the exact size and shape of the hollow flame. The moment the gas is extinguished, or the flame removed to the slightest distance from the solid, the effect as instantly ceases. If the flame be brought successively to the same spot on the solid, the effect grows fainter and finally vanishes, but instantly reappears upon an adjoining portion.

Other combustible gases, such as carbonic oxide, or marsh gas, or olefiant, or coal gas, do not yield this effect, nor does any lamp flame, luminous or otherwise ; nor is it obtained in the oxidising flame of an ordinary blowpipe; but it is imperfectly produced in the reducing flame when coal gas is used; it is not seen when oxygen is driven through coal gas, unless the latter be in excess, and it is poorer and vanishes more quickly with the oxyhydrogen flame than with hydrogen alone. This blue luminosity is, therefore, not a question of heat, bat some property depending either on $(a)$ the chemical nature of hydrogen, or on $(\beta)$ the physical effect of its radiation. At first I thought it was the latter, and that it was a new form of fluorescence, so closely did it resemble those phenomena. But after a week's incessant experimenting, the true cause was hunted down, and found to be dependent on the former effect $(a)$, and in every case ultimately due to the presence of sulphur. A chemically clean body, or a freshly broken surface, did not show the blue coloration; but after exposure for a short time to the air of London, the substance invariably yielded the blueness; this, however, was not the case when the clean surface was covered by a shade, or exposed to the air of the open country. The combustion of coal gas and coal fires yields sulphate of ammonia, a body often deposited in acicular crystals in the glass tubes in a laboratory. Sulphate of ammonia is decomposed by a hydrogen flame, and when that salt is brought into contact with burning hydrogen, it permanently yields the blue colorescence. Hence this body is probably the main source of the blueness seen whenever a hydrogen flame comes into contact with glass tubes or a dirty surface. This effect must repeatedly have been seen by every one who has experimented on singing flames.

When the blueness, as is so often the case, is seen tinging the flame itself, without contact with any body, the sulphur is derived either from the vulcanised tubing, the dust of which is taken up by the passing gas; or if the hydrogen be burnt from the bottle generating it, the blueness is due to the decomposition of the sulphuric acid spray, as will be shown further on.

As a chemical re-agent for detecting sulphur, the delicacy of a hydrogen flame is extraordinary. This fact was estimated as follows:-Pure precipitated silica yields no blueness with the flame; 500 grains of silica were intimately mingled with one grain of milk of sulphur. Less than a $\frac{1}{10}$ th of a grain of this mixture was thrown on the surface of pure water or placed upon chemically clean platinum foil. The water is best, but in either case the blue colour (absent before) now shot forth on bringing the hydrogen flame down. Tried again and again with fresh portions, the effect was very evident, but quickly vanished. The sulphur in a similar portion of the mixture could not be detected chemically by nitro-prusside of sodium. The wonderful sensitiveness of the flame may be still better seen in another way. Immediately after washing, the fingers show no colour when brought for a moment into the flame, but if a white india-rubber tube be touched ever so lightly, the fingers not only show a vivid blueness, but for some time any clean object touched by them, such as platinum foil, shows traces of sulphur by the appearance of the blue coloration with the flame. A block of melting ice continually weeps itself freefrom dust, and thus presents an excellent surface upon which to try the foregoing experiment. Or a plate of platinum, after heating to redness, may be written over with a stick of sulphur. If kept covered, the invisible letiers maylong after be traced out by sweeping the hydrogen flame over the surface of the platinum.

Examined through a prism, the blueness derived from any source shows blue and green bands, similar to the spectrum of sulphur, but I have noticed also a red band. This mode of obtaining a sulphur spectrum suggests further inquiry. White marble smeared over with a bit of sulphur, or with vulcanised rubber tubing, is a convenient source for obtaining the effect at pleasure.

Some sulphates and sulphides show the blueness with the flame, and are evidently decomposed by the hydrogen. Thus sulphate of soda gives no blue appearance, whilst sulphate of ammonia, or alum, does.

$V$. Various liquids were tried in contact with the flame. Sulphuric acid was very notable. Here a magnificent blue effect was observed. For persistence and brilliancy of the colour, this experiment leaves nothing to be desired; the spectrum is very fine. If the liquid is in a glass dish when the flame is brought vertically down, the biueness lights up the glass in a lovely manner.*

VI. But the presence of sulphur is by no means the only body that a hydrogen flame reveals. The least trace of phosphorus is detected by the production of a vivid green light. It is striking to notice the wonderful subdivision of matter in these experiments, and how an immeasurable trace of an element can evoke pronounced and apparently disproportionate effects.

Might not this ready detection of minute quantities of sulphur and phosphorus be of use in the manufacture of iron ; and might not hydrogen introduced into the molten metal be employed for the removal of these great enemies of the iron worker? I speak ignorantly.

VII. Among the range of substances I have tried, tin was found to yield the most conspicuous effect, after the bodies named. A fine scarlet colour is almost instantly produced when the hydrogen flame is brought into contact with tin or any alloy of tin. Tin is somewhat volatile, and its spectrum is rich in red rays. The tin must be clean; or the sulphur blue, which is much brighter, will mask the effect. A charming experiment may be made by partially scraping a soiled surface of tin ; the blue and the scarlet colours mingle, and a lovely purple is the result. When a trace of phosphorus is present there may be obtained a green belt encircling a rich blue, then a purple zone, and finally a glowing scarlet at the root of the flame. These colours, it must be remembered, are not imparted to the flame, but reside on the surface of the body which the flame touches. And where the combustion of the hydrogen is complete, as in the upper part of the flame, or in the luminous stream referred to (II.), these effects are not produced, they are best developed at the root of the flame.

VIII. Passing from liquids and solids, I next tried gases in contact with the flame of hydrogen. Many gases imparted a colour to the flame, but here the effect was

* With all liquicis, but best with marcury, s fine musical note can be oh. tained by causing the jet to dip just below the surface of the liquid. 
different to that previously noticed. The whole flame was tinged with the colour imparted to it. A mere trace of hydrochloric acid gas imparts a reddish brown to the flame; ammonia gas gives a yellow, and burns freely. It is striking to note the combustion of ammonia gas rising from an unstopped bottle that contains the usual solution and which is placed below the flame.

But carbonic acid gas yields the most striking result in contact with the flame. A pale lilac tinge is instantly produced by a stream of this gas. This, I imagine, is due to the decomposition of the carbonic acid by the hydrogen, and the production and combustion of carbonic oxide. For it is at the lower part of the flame that the effect is most marked. One per cent. of pure carbonic acid admitted to a jar of air, can be detected on holding the jar over the flame. The breath, of course, shows the effect most strikingly.

IX. Here then is an eminently practical method of noting the presence of vitiated air in rooms or public buildings. A continuous hydrogen apparatus might be employed with a wash bulb attached. The flame might be burnt from a brass burner or lava jet, placed within a blackened tin cylinder. Opposite the flame a hole might be pierced in the cylinder, and closed by a lens for better viewing the flame within. As soon as the atmosphere in a room becomes unpleasantly vitiated the flame would indicate the fact by its changed colour. A similar apparatus might likewise be employed by miners : in metal mines as a warning against impure air, and in coal mines as a detector of fire damp. In this latter case the ends of the cylinder could be covered with wire gauze.

To this practical aspect of the question I am now giving such little leisure as I possess.

The results thus briefly described demonstrate-

I. That the combustion of hydrogen exhibits some physical peculiarities, and produces phosphorescence on many substances with which it comes in contact.

2. That the blueness so often seen in a hydrogen flame is due to the presence of sulphur, derived either from the vulcanised rubber tubing, or from atmospheric dust, or from the decomposition of the sulphuric acid spray from the generator.

3. That a flame of hydrogen forms an exceedingly delicate re-agent for the detection of sulphur or phosphorus, and possibly also of tin.

4. That many sulphates, and also carbonic acid, are apparently decomposed by a hydrogen flame.

5. That a hydrogen flame is further a test for the presence of some gases, notably carbonic acid.

6 . That these results are capable of practical application. W. F. BARRETT

International College, Spring Grove, W.

\section{THE INHABITANTS OF THE MAMMOTH CAVE OF KENTUCKY}

\section{CRUSTACEANS AND INSECTS}

(Concluded from page 448)

NEXT to the blind fish, the blind crawfish attracts the attention of visitors to the cave. This is the Cambarus pellucidus (Fig. Io, p. 486, from Hagen's monograph of the North American Astacidæ) first described by Dr. Tellkampf. He remarks that "the eyes are rudimentary in the adults, but are larger in the young." We might add that this is an evidence that the embryo develops like those of the other species; and that the inheritance of the blind condition is probably due to causes first acting on the adults and transmitted to their young, until the production of offspring that become blind becomes a habit. This is a partial proof at least that the characters separating the genera and species of animals are those inherited from adults, modified by their physical surroundings and adap. tations to changing conditions of life, inducing certain alterations in parts which have been transmitted with more or less rapidity, and become finally fixed and habitual. Prof. Hagen has seen a female of Cambarus Bartonii from Mammoth Cave, "with the eyes well developed,". and a specimen was also found by Mr. Cooke. Prof. Hagen remarks that " $C$. pellucidus is the most aberrant species of the genus. The eyes are atrophied, smaller at the base, conical, instead of cylindrical and elongated, as in the other species. The cornea exists, but is small, circular, and not faceted; the optic fibres and the dark-coloured pigments surrounding them in all other species are not developed." It seems difficult for one to imagine that our blind crawfish was created suddenly, without the intervention of secondary laws, for there are the eyes more perfect in the young than the adult, thus pointing back to ancestors unlike the species now existing. We can now understand, why embryologists are anxiously studying the embryology of animals to see what organs or characteristics are inherited, and what originate de novo, thus building up genealogies, and forming almost a new department of science,-comparative embryology in its truest and widest sense.

Of all the animals found in caves, either in this country or Europe, perhaps the most strange and unexpected is the little creature of which we now speak. It is an Isopod crustacean, of which the pill bugs or sow bugs are examples. A true species of pill bug (Titanethes albus Schiödte) inhabits the caves of Carniolia, and it is easy to believe that one of the numerous species of this group may have become isolated in these caves and modified into its present form. So also with the blind Niphargus stygizs of Europe, allied to the fresh water Gammarus so abundant in pools of fresh water. We can also imagine how a species of Asellus, a fresh water Isopod, could represent the Idoteidæ in our caves, and one may yet be found; but how the present form became a cave dweller is difficult of explanation, as its nearest allies are certain species of Idotea which are all marine, with the exception of two species: $I$. entomon, living in the sea and also in the depths of the Swedish lakes, as discovered by Loven, the distinguished Swedish naturalist, while a species representing this has been detected by Dr. Stimpson at the bottom of Lake Michigan. Our cave dweller is nearly allied to Idotea, but differs in being blind, and in other particulars, and may be called Cacidotea stygia." (Fig. II side view, enlarged; Fig. I 2 dorsal view; $b$, inner antenna ; $c$, Ist leg.) It was found creeping over the fine sandy bottom, in company with the Campodea, in a shallow pool of water four or five miles from the mouth of the cave.

This closes our list of known articulates from this and other caves in this country, the result of slight explorations by a few individuals. The number will doubtless be increased by future research. It is to be hoped that our western naturalists will thoroughly explore all the sinks and holes in the cave country of the western and middle states. The subject is one of the highest interest in a soological point of view, and from the light it throws on

* Generic characters. Head large, much thicker than the body, and as long as broad; subcylindrical, rounded in front. No eyes. First antennz slender, 8-jointed (2nd antennæ broken off). Abdominal segments consolidated into one piece. Differs chiefly from Idotea, to which it is otherwise closely allied, by the 8-jointed (instead of 4 -jointed rst (inner) antennx. the very large head, and by the absence of any traces of the three basal segments of the abdomen usually present in Idolea. Specific characters. Body smooth, pure white; tegument thin, the viscera appearing through. Head as wide as succeeding segment, and a little more than twiee as long. Inner antenna minute, slender, the four basal joints of nearly equal ler.gth, though the fourth is a little smaller than the basal three, remaining four joints much smaller than others, being one-half as thick and two-thirds as long as either of the four basal joints; ends of last four joints a little swollen, giving rise to two or three hairs; terminal joint ending in a more distinct knoh, and bearing five hairs. Segment of thorax very distinct, sutures deeply incised: edges of segments pilose; abdomen flat above, rounded behind, with a very slight median projection : the entire pair of gills do not reach to the end of the abdomen, shorter, but no smaller than the second. Length' 25 inch. 